\title{
Editorial
}

\section{Non-invasive mechanical ventilation in COPD}

\author{
Ahmed Fayed ${ }^{*}$ \\ King Abdul-Aziz specialized hospital, Taif, Saudi Arabia. \\ *Corresponding author: Ahmed Fayed, King Abdul-Aziz specialized hospital, Taif, Saudi Arabia., \\ E-mail: chestradiology@yahoo.com
}

Received Date: 25 September 2018; Accepted Date: 01 October 2018; Published Date: 15 October 2018

Chronic obstructive pulmonary disease (COPD) is defined as a common, preventable and treatable disease that is characterized by persistent respiratory symptoms and airflow limitation resulted from airway and/or alveolar abnormalities usually caused by significant exposure to noxious particles or gases and include chronic bronchitis, emphysema and chronic remodelling bronchial asthma [1].

Treatment of COPD include many pharmacological and non pharmacological interventions but still smoking cessation is the most important action. The main stay of pharmacological treatment is inhaled bronchodilators and inhaled steroids if FEV1 less than $50 \%$. The non pharmacological interventions include quit smoking, pulmonary rehabilitation, Non invasive mechanical ventilation (NIMV) and surgical procedures (lung volume reduction surgery, bullectomy, lung transplantation) together with nutritional, social and psychiatric management $[2,3]$.

NIMV is a mechanical respiratory support delivered via an interface (eg, nasal prongs or mask, face mask, or helmet) without the endotracheal intubation to give a continuous positive airway pressure (CPAP) or bilevel positive airway support (BiPAP) [4] resulted in many positive outcomes in management of COPD patients not only during exacerbation but also in stable state $[5,6]$.

Hypercapnea in COPD is largely due to Respiratory muscle weakness resulted from diaphragmatic dysfunction (from hyperinflation), nutritional deficiencies and exhaustion from excessive work load [7].

By providing a rest for weakened respiratory muscles, the nocturnal NIMV can improve nocturnal and daytime respiratory function in advanced COPD with hypercapnia and oxygen desaturation during sleep despite the use of supplemental oxygen at $\geq 2 \mathrm{~L} / \mathrm{min}[8,9]$ resulted in improved sleep quality and initial nocturnal hypercapnia with prolongation of the time to readmission or death compared with supplemental oxygen alone $[10,11]$.

Hypercapnea and gas exchange abnormalities in COPD not only due to respiratory muscle weakness but also may result from associated sleep-related breathing disorders or heart failure so it is preferred to do Polysomnography (PSG) and echocardiogram for best plan selection for the patient[11].

COPD exacerbation is an acute worsening of the patient's respiratory symptoms exceeding normal day to day variation and require a different plan for his management including NIMV [1].

In COPD exacerbation, NIMV indicated after failure of others immediate maximal measures in patient with hypercapnic acidosis ( $\mathrm{PaCO} 2>45 \mathrm{mmHg}$ or $\mathrm{pH}<7.30$ ) who do not need intubation and lack contraindications to NIV leading to decrease need for invasive mechanical ventilation with decrease morbidity and mortality $[12,13,14]$. For these patients frequent clinical monitoring is recommended every 15 minutes in the first hour; every 30 minutes in the next 3 hours then hourly for 8 hours [15]. Further continuation of NIMV as long as possible with Minimum 6 hours is advised for Patients who show initial improvements during the first few hours of treatment with suitable interruptions for oral intake, nebulisers etc[16]

Lastly a benefit from NIMV that is clearly observed in intubated patient for sever COPD exacerbation is the prevention of post-extubation respiratory failure and need for reintubation [17].

\section{Conclusion}

Although annoying for the patient and hardly to be explained by doctors, NIMV play an important role in patient with COPD not only during exacerbation but also in stable state with decrease in morbidity, hospital stay, intubation rate, frequency of exacerbations and mortality if the patients meet the its criteria with good compliance to it. .

\section{References}

1. Global Initiative for Chronic Obstructive Lung Disease (GOLD) (2018) Global Strategy for the Diagnosis, Management and Preven- 
tion of chronic obstructive pulmonary disease: 2018 Report.

2. Peter GG (2001) Management of chronic obstructive pulmonary disease (COPD). Aust Prescr 24: 152-155.

3. MacNee W, Calverley PMA (2003) Chronic obstructive pulmonary disease• 7: management of COPD. Thorax 58: 261-265.

4. Najaf-Zadeh A, Leclerc F (2011) Non-invasive positive pressure ventilation for acute respiratory failure in children: a concise review. Ann Intensive Care 1: 15

5. Lindenauer PK, Stefan MS, Shieh MS, Pekow PS, Rothberg MB, et al. (2014) Outcomes associated with invasive and non-invasive ventilation among patients hospitalized with exacerbations of chronic obstructive pulmonary disease. JAMA Intern Med 174: 1982-1993.

6. Wedzicha JA, Miravitlles M, Hurst JR, et al. (2017) Management of COPD exacerbations: European Respiratory Society/American Thoracic Society. Eur Respir J 49: 1600791.

7. Rochester DF, Braun NM, Arora NS (1979) Respiratory muscle strength in chronic obstructive pulmonary disease. Am Rev Respir Dis 119: 151-154.

8. Schonhofer B, Polkey MI, Suchi S, Köhler D (2006) Effect of home mechanical ventilation on inspiratory muscle strength in COPD. Chest 130: 1834-1838.

9. Theerakittikul T, Ricaurte B, Aboussouan LS (2010) Non-invasive positive pressure ventilation for stable outpatients: CPAP and beyond. Cleve Clin J Med 77: 705-714.

10. Murphy PB, Rehal S, Arbane G, Bourke S, Calverley PMA, et al (2017) Effect of Home Non invasive Ventilation With Oxygen Therapy vs Oxygen Therapy Alone on Hospital Readmission or Death
After an Acute COPD Exacerbation: A Randomized Clinical Trial. JAMA 317: 2177-2186.

11. McEvoy RD, Pierce RJ, Hillman D, Esterman A, Ellis EE, et al. (2009) Australian trial of non-invasive Ventilation in Chronic Airflow Limitation (AVCAL) Study Group. Nocturnal non-invasive nasal ventilation in stable hypercapnic COPD: a randomised controlled trial. Thorax 64: 561-567.

12. Lindenauer PK, Stefan MS, Shieh MS, Pekow PS, Rothberg MB, et al. (2014) Outcomes associated with invasive and non-invasive ventilation among patients hospitalized with exacerbations of chronic obstructive pulmonary disease. JAMA Intern Med 174: 1982-1993.

13. Elliott MW, Nava S (2012) Non-invasive ventilation for acute exacerbations of chronic obstructive pulmonary disease: "Don't think twice, it's alright!". Am J Respir Crit Care Med 185: 121-123.

14. Wedzicha JA, Miravitlles M, Hurst JR, et al. (2017) Management of COPD exacerbations: a European Respiratory Society/American Thoracic Society guideline. Eur Respir J 49: 1600791.

15. Robino C, Faisy C, Diehl J-L et al. (2003) Effectiveness of non-invasive positive pressure ventilation differs between decompensated chronic restrictive and obstructive pulmonary disease patients. In Care Med 29: 603-610.

16. Plant PK, Owen JL, Elliott MW (2000) Early use of non-invasive ventilation for acute exacerbations of chronic obstructive pulmonary disease on general respiratory wards: a multicentre randomised controlled trial. Lancet 355: 1931-1935.

17. Rochwerg B, Brochard L, Elliott MW, Hess D, Hill NS, et al. (2017) Official ERS/ATS clinical practice guidelines: non-invasive ventilation for acute respiratory failure. Eur Respir J 50: 1602426. 